\title{
Photo-Catalytic Remediation of Pesticides in Wastewater Using $\mathrm{UV} / \mathrm{TiO}_{2}$
}

\author{
Mohamed H. EL-Saeid ${ }^{1, *}$, Modhi O. Alotaibi ${ }^{2, * \mathbb{D}}$, Mashael Alshabanat ${ }^{3, *}$, Khadiga Alharbi ${ }^{2}$, \\ Abeer S. Altowyan ${ }^{4}$ and Murefah Al-Anazy ${ }^{3}$
}

1 Chromatographic Analysis Unit, Soil Science Department, College of Food \& Agricultural Sciences, King Saud University, P.O. Box 2460, Riyadh 11451, Saudi Arabia

2 Department of Biology, College of Science, Princess Nourah Bint Abdulrahman University, P.O. Box 88828, Riyadh 11671, Saudi Arabia; kralharbi@pnu.edu.sa

3 Department of Chemistry, College of Science, Princess Nourah Bint Abdulrahman University, P.O. Box 88828, Riyadh 11671, Saudi Arabia; mmalanazy@pnu.edu.sa

4 Department of Physics, College of Science, Princess Nourah Bint Abdulrahman University, P.O. Box 88828, Riyadh 11671, Saudi Arabia; asaltowyan@pnu.edu.sa

* Correspondence: elsaeidm@ksu.edu.sa (M.H.E.-S.); mouotaebe@pnu.edu.sa (M.O.A.); mnalshbanat@pnu.edu.sa (M.A.)

check for updates

Citation: EL-Saeid, M.H.; Alotaibi, M.O.; Alshabanat, M.; Alharbi, K.; Altowyan, A.S.; Al-Anazy, M. Photo-Catalytic Remediation of Pesticides in Wastewater Using $\mathrm{UV} / \mathrm{TiO}_{2}$. Water 2021, 13, 3080. https://doi.org/10.3390/w13213080

Academic Editor: Chengyun Zhou

Received: 28 July 2021

Accepted: 21 October 2021

Published: 2 November 2021

Publisher's Note: MDPI stays neutral with regard to jurisdictional claims in published maps and institutional affiliations.

Copyright: (c) 2021 by the authors. Licensee MDPI, Basel, Switzerland. This article is an open access article distributed under the terms and conditions of the Creative Commons Attribution (CC BY) license (https:// creativecommons.org/licenses/by/ $4.0 /)$.

\begin{abstract}
One of the most serious environmental concerns worldwide is the consequences of industrial wastes and agricultural usage leading to pesticide residues in water. At present, a wide range of pesticides are used directly to control pests and diseases. However, environmental damage is expected even at their low concentration because they are sustained a long time in nature, which has a negative impact on human health. In this study, photolysis and photocatalysis of the pesticides dieldrin and deltamethrin were tested at two UV wavelengths (254 and $306 \mathrm{~nm}$ ) and in different test media (distilled water, wastewater, and agricultural wastewater) to examine their ability to eliminate pesticides. $\mathrm{TiO}_{2}(0.001 \mathrm{~g} / 10 \mathrm{~mL})$ was used as a catalyst for each treatment. The purpose was to determine the influence of UV wavelength, exposure time, and catalyst addition on the pesticide decomposition processes in different water types. Water was loaded with the tested pesticides $(2000 \mu \mathrm{g})$ for $12 \mathrm{~h}$ under UV irradiation, and the pesticide concentrations were measured at $2 \mathrm{~h}$ intervals after UV irradiation. The results showed a clear effect of UV light on the pesticides photodegradations that was both a wavelength- and time-dependent effect. Photolysis was more effective at $\lambda=306 \mathrm{~nm}$ than at $\lambda=254 \mathrm{~nm}$. Furthermore, $\mathrm{TiO}_{2}$ addition $(0.001 \mathrm{~g} / 10 \mathrm{~mL})$ increased the degradation at both tested wavelengths and hence could be considered a potential catalyst for both pesticide degradations. Deltamethrin was more sensitive to UV light than dieldrin under all conditions.
\end{abstract}

Keywords: photolysis; catalysis; degradation; pesticides; UV; wastewater; agricultural wastewater

\section{Introduction}

Agrochemicals are substances that are commonly used in agriculture to protect crops and ensure their productivity [1]. Such chemicals are commonly applied to eliminate pests (such as rodents), and include pesticides-namely, insecticides, fungicides, and herbicides-and un-wanted plants [2]. In public health, agrochemicals are used to combat human disease vectors such as mosquitoes; they are also used against crop-damaging epidemics in the agricultural sector $[3,4]$ that also offer producers an efficient means to manage crop pests that decrease yield and threaten food security [5]. While some are used at a crop's initial production stage, others are generally used on edible plant parts before harvest or even during storage. Therefore, crop-based agrochemicals such as pesticides are dissolved in water, and the crop are sprayed in the fields.

Many new pesticides have been introduced over the last few decades, which have toxic effect in the short and/or long term [3,4]. Commercial pesticide formulations often include additional compounds (such as solvents and surfactants) to increase their 
activity; solvents and other co-formulants often increase the environmental impact of the formulation as well.

The potential harmful effects of used pesticide on both humans and the environment have received growing attention from the community and expert authorities. Numerous studies have focused on health or environmental concerns from accidental or intentional pesticide exposure, specifically those highly toxic to mammals or found in the environment. The pesticide's risks should be reduced to their minimum via careful regulation and appropriate user guidance. However, the positive effects of pesticide use should not be overlooked. When rational, careful use of pesticides in combination with other technologies is considered in integrated pest management systems, their usage is likely to be justified [6].

On the other hand, fresh fruit and vegetable growers use various water sources, including surface water sources (such as rivers or lakes) that are potentially contaminated by chemical pollutants [7]. Thus, the water used in agricultural production increasingly might have the potential to introduce pathogenic viruses into fresh produce supply chains. The Codex Committee on Pesticide Residues' Code of Hygienic Practice for Fresh Fruits and Vegetables (adopted in 2003; revision in 2010 (new Annex III for Fresh Leafy 334 Vegetables), from the Netherlands, March 2010 [7], pointed out the importance of using 'clean water' for fresh produce cultivation, particularly if water is applied before harvest and in close contact with the edible plant part. Environmental protection programs seek to encourage a reduction in the use of pesticides as a precaution product in growing crops [8].

One of the most abundant water contaminants is pesticide residue, and despite pesticides' economic advantages, such as high crop yields, their potential health hazards are still unknown. Water bodies are polluted by toxic chemicals resulting from human activities in industry, agriculture, and housing [9]. The residues of industrial and agricultural areas contaminated with pesticides are dumped unattended into the nearby water bodies, although most of them are not degradable in water, and thus the aquatic environment becomes threatened [10]. The effects of pollutants are generally characterized by alteration in the animal physiological behavior, and therefore affect survival, reproduction, and growth.

Most Europeans are concerned primarily with the long-term or chronic consequences of low exposure levels through various pathways, especially residues in food crops, as well as through pesticide fraction losses from the target areas [11].

Dieldrin and deltamethrin are environmental pollutants with long-term adverse effects. The use of dieldrin has been banned in most countries around the world primarily for environmental reasons. The widespread use of dieldrin and its ecological persistence have resulted in survival in the environment [12], with bioaccumulation in the food chain due to their low volatile, chemically stable, and lipophilic properties [13]. The half-life of dieldrin is about 5 years [14]. In addition, it will take 25 years for $90 \%$ to disappear [15] and remains for 60 years when not exposed to sunlight. In addition, it was used for termite control until about 1985, which means it is still in the basement of the most houses right now and in the soils of agricultural fields with these pesticides [16]. In a previous study published in 2005 [17], Saqib et al. identified residues of DDT, DDE, aldrin, dieldrin, and deltamethrin in fish tissues in Haleji Lake, and more different pesticide compounds were identified in Kalri Lake, possibly because of runoff from surrounding agricultural farms [17]. On the other hand, in Saudi Arabia at Al-Qassim, high pesticide concentrations might be linked to intensive agricultural activity [18]. Researchers [19] stated that dieldrin and deltamethrin are pesticides found in fruits and palm in Riyadh market, Saudi Arabia, which might suggest contamination of irrigation water. The search for a potential tool such as photolysis for the above-mentioned pesticide residue degradation is important.

Recent studies are starting to shed light on disposal strategies for pesticides in contaminated water that would lead to better effluent water quality and have focused on the possibility of analyzing pollutants and removing pollution by available and less expensive methods [20-25]. Currently, several processes have been developed to reduce harmful pollutants in wastewater, including advanced oxidation processes (AOP) [26], activated sludge treatments [27], electro-removal [28], ozonation [29], sunlight [30], UV radiation [31], 
and combined/integrated methods [32]. Catalyst methodologies have also been used to improve the pesticide disposal mechanism. Photodegradation is induced by the action of light and is attributed to chemical reactions arising by photoionization. Researchers [33] explained that one of the most important abiotic transformations of pesticides in the aquatic environment is photolysis, where the high energy of solar rays causes characteristic reactions such as bond separation, rotation, and rearrangement. Photolysis with the aid of catalytic compounds could be beneficial when UV radiation is applied. UV radiation has adequate energy for chemical bond breakdown; the high-energy photons cause ionization.

Dieldrin and deltamethrin are environmental pollutants that are prohibited in most countries around the world, but they are still used, leading to contamination of many environments, such as soil, sediment, and groundwater [16,34]. Therefore, looking for solution to reduce their negative impact is an urgent issue. UV has been well known as water disinfectant for microbial removal $[35,36]$, and as an efficient technique for the treatment of wastewater [37]. However, new studies to develop the photo-remediation by UV radiation as an effective method for water treatment systems are needed.

The purpose of this work was to obtain information that is currently lacking regarding the photo-remediation of the pesticides dieldrin and deltamethrin, since their high levels in contaminated water are expected and attributed to pollution as consequences to industrial wastes and agricultural usage. Therefore, in this study, different types of water contaminated with dieldrin and deltamethrin were irradiated at two UV wavelengths, with and without a catalyst, to observe the effect of the potential catalyst and identify the most effective UV wavelength and time span for maximum pesticide decomposition.

The importance of this study is in the remediation of dieldrin- and deltamethrinpolluted water taken from the local environment, including treated wastewater and agricultural wastewater. It will provide new data and potential breakthroughs to scientists, especially those working in environmental pollution and water remediation.

\section{Materials and Methods}

\subsection{Study Samples}

Three water samples were used as targets in the study: distilled water, wastewater, and agriculture wastewater. The distilled water used was obtained from a Millipore distilled water system (College of Food and Agricultural Sciences, King Saud University, Riyadh, Saudi Arabia).

First, $5 \mathrm{~L}$ of the wastewater sample was taken in dark glass container from treatment plants at Al Mansuriyah, Riyadh $(\mathrm{pH}=7.33, \mathrm{EC}=1.77 \mu \mathrm{S} / \mathrm{cm}, \mathrm{TDS}=1133 \mathrm{mg} / \mathrm{L}$, turbidity $=1.89 \mathrm{NTU}$ ) where the treatment process was performed by activated sludge method using tertiary treatment, and $5 \mathrm{~L}$ of the agriculture wastewater was taken from the Al-Kharj agricultural region $(\mathrm{pH}=8.42, \mathrm{EC}=2.48 \mu \mathrm{S} / \mathrm{cm}, \mathrm{TDS}=1579 \mathrm{mg} / \mathrm{L}$, turbidity $=3.24 \mathrm{NTU})$. The crops produced by the farms were corn, grains, dates, and some vegetables and leafy crops.

Both samples were transferred under cooling within $2 \mathrm{~h}$ to the analysis and experimental lab. Wastewater samples were analyzed for pesticide residues within $24 \mathrm{~h}$ and then the treatment of remediation began.

Pesticide residues in the collected wastewater samples were analyzed before spik-ing with $2000 \mathrm{ppb}$ concentration of dieldrin and deltamethrin.

\subsection{Standards and Reagents}

Dieldrin, deltamethrin (Table 1 and Figure 1), calibration, and injection standards (99.9\% purity) were purchased from AccuStandard, Inc., New Haven, CT, USA as individual or mixture standards at concentrations of $10 \mu \mathrm{g} / \mathrm{mL}$. All internal standards were 13C 12-labelled (13C-labelled compound use allowed for the analysis to be quantified without clean up). All solvents used for the extraction and analysis of pesticides were analysis-grade residues ( $99.9 \%$ purity) and were obtained from Fisher Scientific (Fair Lawn, NJ, USA). QuEChERS kits were purchased from Phenomenex (Torrance, CA, USA). Titanium dioxide $\left(\mathrm{TiO}_{2}\right)$ as a photocatalyst was from Sigma-Aldrich Chemie $\mathrm{GmbH}$, Germany 
(molecular weight: 79.87, CAS Number: 13463-67-7, 718467nanopowder, $21 \mathrm{~nm}$ primary particle size (TEM), $\geq 99.5 \%$ trace metals basis).

Table 1. Chemical properties of pesticides.

\begin{tabular}{cccccc}
\hline Pesticides & $\begin{array}{c}\text { Molecular } \\
\text { Formula }\end{array}$ & Molecular Weight & Solubility & Type & Effective against \\
\hline Dieldrin & $\mathrm{C}_{12} \mathrm{H}_{8} \mathrm{Cl}{ }_{6} \mathrm{O}$ & $380.895 \mathrm{~g} / \mathrm{mol}$ & soluble in water & $\begin{array}{c}\text { organochlorine } \\
\text { insecticide }\end{array}$ & $\begin{array}{c}\text { controlling locusts, } \\
\text { vectors, tropical } \\
\text { disease, and termites }\end{array}$ \\
\hline Deltamethrin & $\mathrm{C}_{22} \mathrm{H}_{19} \mathrm{Br}_{2} \mathrm{NO}_{3}$ & $505.206 \mathrm{~g} / \mathrm{mol}$ & soluble in water & $\begin{array}{c}\text { pyrethroid ester } \\
\text { pesticide }\end{array}$ & $\begin{array}{c}\text { controlling malaria } \\
\text { vectors }\end{array}$ \\
\hline
\end{tabular}

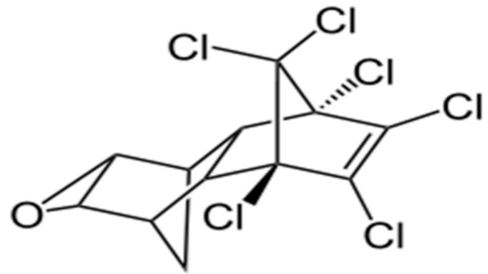

Dieldrin

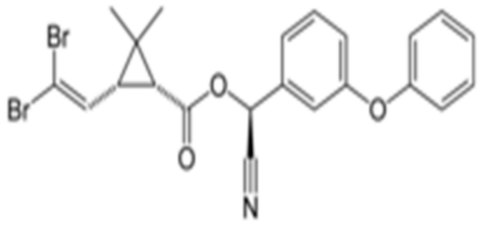

Deltamethrin

Figure 1. A structure of Dieldrin and deltamethrin.

\subsection{Sample Remediation by UV Photolysis (UV)}

The water was photo-treated using ultraviolet radiation at 254 and $306 \mathrm{~nm}$ wavelengths for the two pesticides' decomposition. Boekel UV Crosslinker (BUV) model 234100-2: 230 VAC, $175 \mathrm{~W}, 0.8$ A was applied with four $254 \mathrm{~nm}$ lamps and Boekel Scientific, 855 Pennsylvania Blvd. Feasterville, PA, USA with four $306 \mathrm{~nm}$ lamps. The lamps and water samples were at a $15 \mathrm{~cm}$ distance at $1071 \mu \mathrm{Wcm}^{-2}$ intensity of UV irradiation. Each pesticide (approximately $2000 \mu \mathrm{g} / \mathrm{L}$ ) was loaded into the water and incubated for $12 \mathrm{~h}$ under UV lighting. Samples were taken for pesticide quantity residue measurement at $2 \mathrm{~h}$ intervals to identify the correct UV wavelength and the photolysis process exposure time. Furthermore, the same procedure was repeated for each pesticide with the addition of $0.001 \mathrm{~g} \mathrm{TiO}_{2}$ to each $10 \mathrm{~mL}$ water sample to study the effect of the catalyst.

\subsection{Samples Extraction and Cleanup by QuEChERS}

First, $10 \mathrm{~mL}$ of the water sample was transferred into a $50 \mathrm{~mL}$ centrifuge tube and vortexed briefly. After that, $10 \mathrm{~mL}$ acetonitrile was added to each sample and shaken using a vortex for $5 \mathrm{~min}$ to extract the pesticides, using a Spex Sample Prep Geno/Grinder 2010 operated at $1500 \mathrm{rpm}$. Next, the contents of an ECQUEU750CT-MP (citrate salts) Mylar pouch were added to each centrifuge tube. The samples were then shaken for at least $2 \mathrm{~min}$ and centrifuged for $5 \mathrm{~min}$ at $\geq 3500 \mathrm{rcf}$. A $1 \mathrm{~mL}$ aliquot of supernatant was transferred to a $2 \mathrm{~mL}$ CUMPSC18CT $\left(\mathrm{MgSO}_{4}\right.$, PSA, C18) dSPE tube. The samples were shaken in a vortex for about $1 \mathrm{~min}$, then centrifuged for $2 \mathrm{~min}$ at high rcf (e.g., $\geq 5000$ ). The purified supernatant was filtered through a $0.2 \mu \mathrm{m}$ syringe filter directly into a GC sample vial, and thereafter the sample was kept for further analysis.

\subsection{Analysis by Triple-Quadrupole Gas Chromatography Mass Spectrometry (GCMSMSTSQ 8000/SRM)}

The analysis was carried out using the latest Thermo Scientific ${ }^{\mathrm{TM}} \mathrm{TSQ} 8000^{\mathrm{TM}}$ triplequadrupole GC-MS/MS system equipped with the Thermo Scientific ${ }^{\text {TM }}$ TRACE $^{\text {TM }} 1310$ GC with SSL Instant Connect ${ }^{\mathrm{TM}}$ SSL module and Thermo Scientific ${ }^{\mathrm{TM}}$ TriPlus $^{\mathrm{TM}}$ RSH auto sampler (Waltham, MA, USA). The transition conditions are presented in Table 2. 
Table 2. GCMSMSTQD 8000 SRM instrumental conditions.

\begin{tabular}{|c|c|c|c|}
\hline \multicolumn{2}{|c|}{ GC Trace Ultra Conditions } & \multicolumn{2}{|c|}{ TSQ Quantum MS/MS Conditions } \\
\hline Column & TR-Pesticide $30 \mathrm{~m} \times 0.25 \mathrm{~mm} \times 0.25 \mu \mathrm{m}$ & Ionization mode & EI \\
\hline Injector & Splitless & Electron energy & $70 \mathrm{eV}$ \\
\hline Injected volume & $1 \mu \mathrm{L}$ & Emission current & $50 \mu \mathrm{A}$ \\
\hline Injector temperature & $225^{\circ} \mathrm{C}$ & Q1/Q3 resolution & $0.7 \mathrm{u}(\mathrm{FWHM})$ \\
\hline Carrier gas & Helium, $1.2 \mathrm{~mL} / \mathrm{min}$ & Collision gas & Argon \\
\hline Oven program & $\begin{array}{l}80^{\circ} \mathrm{C} \text { hold } 1 \mathrm{~min} 15^{\circ} \mathrm{C} / \mathrm{min} \text { to } 160^{\circ} \mathrm{C} \\
\text { hold } 1 \mathrm{~min} 2.2^{\circ} \mathrm{C} / \mathrm{min} \text { to } 230^{\circ} \mathrm{C} \text { hold } \\
1 \mathrm{~min} 5^{\circ} \mathrm{C} / \mathrm{min} \text { to } 290^{\circ} \mathrm{C} \text { hold } 5 \mathrm{~min} \text {, } \\
\text { Run time: } 57.15 \mathrm{~min}\end{array}$ & Operating mode & Selected reaction monitoring (SRM) \\
\hline \multirow[t]{2}{*}{ Transfer line temperature } & $280^{\circ} \mathrm{C}$ & Collision gas pressure & 1 mTorr \\
\hline & & Polarity & Positive \\
\hline
\end{tabular}

\subsection{QAQC Strategies and Method Performance}

For quality analysis and quality control, samples were prepared in triplicate, blanked, and spiked. Certified reference material (CRM) was prepared and processed with each batch (5-10 samples) analyzed. QuEChERS and GCMSMSTSQ 8000/SRM method limit detection (LOD) and limit quantification (LQD), repeatability, reproducibility, accuracy, and precision were also determined for each pesticide (Table 3 ).

Table 3. Parameters of retention time, LOD, LOQ, recovery\%, and GCMSTQD target mass of SRM scanning mode.

\begin{tabular}{|c|c|c|c|c|c|c|c|c|c|}
\hline Name & RT min & Mass & $\begin{array}{l}\text { Product } \\
\text { Mass }\end{array}$ & $\begin{array}{c}\text { Collision Energy } \\
\mathrm{m} / \mathrm{z}\end{array}$ & $\begin{array}{c}\text { LOQ } \\
\mathrm{ng} / \mathrm{ml}\end{array}$ & $\begin{array}{c}\text { LOD } \\
\mathrm{ng} / \mathrm{mL}\end{array}$ & $r^{2}$ & $\begin{array}{c}\text { Recovery } \\
\%\end{array}$ & SD \\
\hline Deltamethrin & 21.4 & 176 & 124 & 9 & 3.6 & 1.2 & 0.8034 & 102.4 & 8.3 \\
\hline Dieldrin & 30.5 & 279 & 243 & 10 & 7.9 & 5.3 & 0.9486 & 105.5 & 7.1 \\
\hline
\end{tabular}

\section{Results and Discussion}

\subsection{Photolysis Process}

The photolysis process of dieldrin and deltamethrin was examined in the current study for three different types of water: distilled water (DW), wastewater (WW). and agricultural wastewater (Ag.WW) using UV radiation at varied wavelengths with and without a catalytic agent $\left(\mathrm{TiO}_{2}\right)$. The results indicated that the amount of both dieldrin and deltamethrin decreased gradually with increasing time after photolysis. The pesticides' degradation rate and reduction (\%) was calculated as the variation between the concentration after treatment in relation to that before treatments. The reduction percentage in the concentration of pesticide residues after degradation process for dieldrin and deltamethrin in DW reached $39.35 \%$ and $73.6 \%$ at $254 \mathrm{~nm}$ and $43.95 \%$ and $76.55 \%$ at $306 \mathrm{~nm}$, respectively, after $12 \mathrm{~h}$ of treatment. As for WW, reduction percentages of $43.3 \%$ and $83.8 \%$ at $254 \mathrm{~nm}$ and $49.3 \%$ and $84.35 \%$ were recorded after $12 \mathrm{~h}$ for dieldrin and deltamethrin, respectively, at $306 \mathrm{~nm}$. Furthermore, in Ag.WW, the percentages of reduction of dieldrin and deltamethrin after $12 \mathrm{~h}$ were $58.8 \%$ and $46.8 \%$ at $254 \mathrm{~nm}$ versus $52.9 \%$ and $37.3 \%$ at $306 \mathrm{~nm}$, respectively. It was observed that the longer UV wavelength $(306 \mathrm{~nm})$ had a higher capacity for pesticide degradation compared to $254 \mathrm{~nm}$. The dieldrin and deltamethrin amounts in DW, WW, and Ag.WW samples were decreased with increased UV exposure time as indicated in Figures 2-4, and therefore, a time-dependent reduction was noted. 

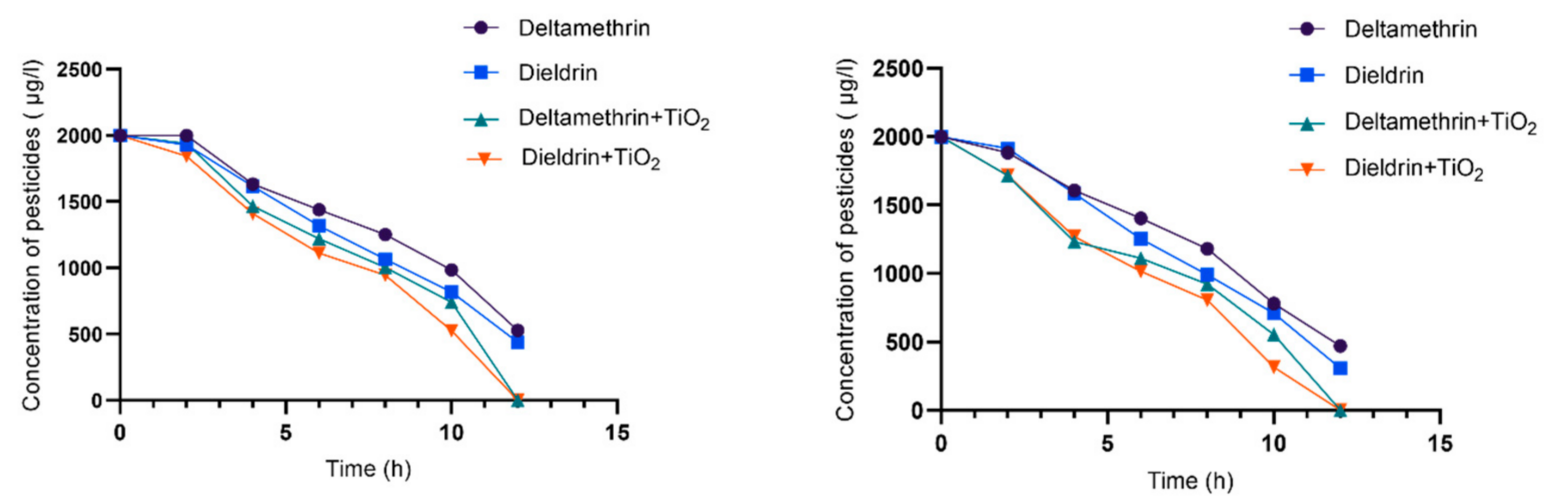

Figure 2. Concentration of pesticides ( $\mu \mathrm{g} / \mathrm{L}$ ) versus exposure time of UV radiation for photolysis process at $254 \mathrm{~nm}(\mathbf{l e f t})$ and $306 \mathrm{~nm}$ (right) in distilled water with and without the catalytic agent.
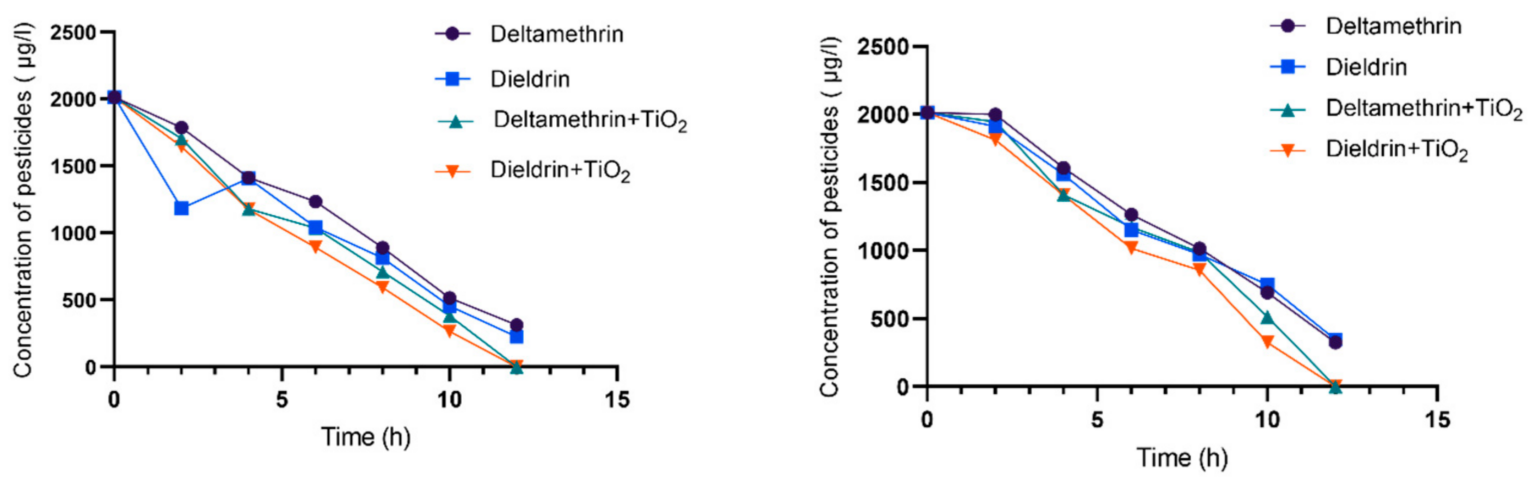

Figure 3. Concentration of pesticides ( $\mu \mathrm{g} / \mathrm{L}$ ) versus exposure time of UV radiation for photolysis process at $254 \mathrm{~nm}(\mathbf{l e f t})$ and $306 \mathrm{~nm}$ (right) in wastewater with and without the catalytic agent.
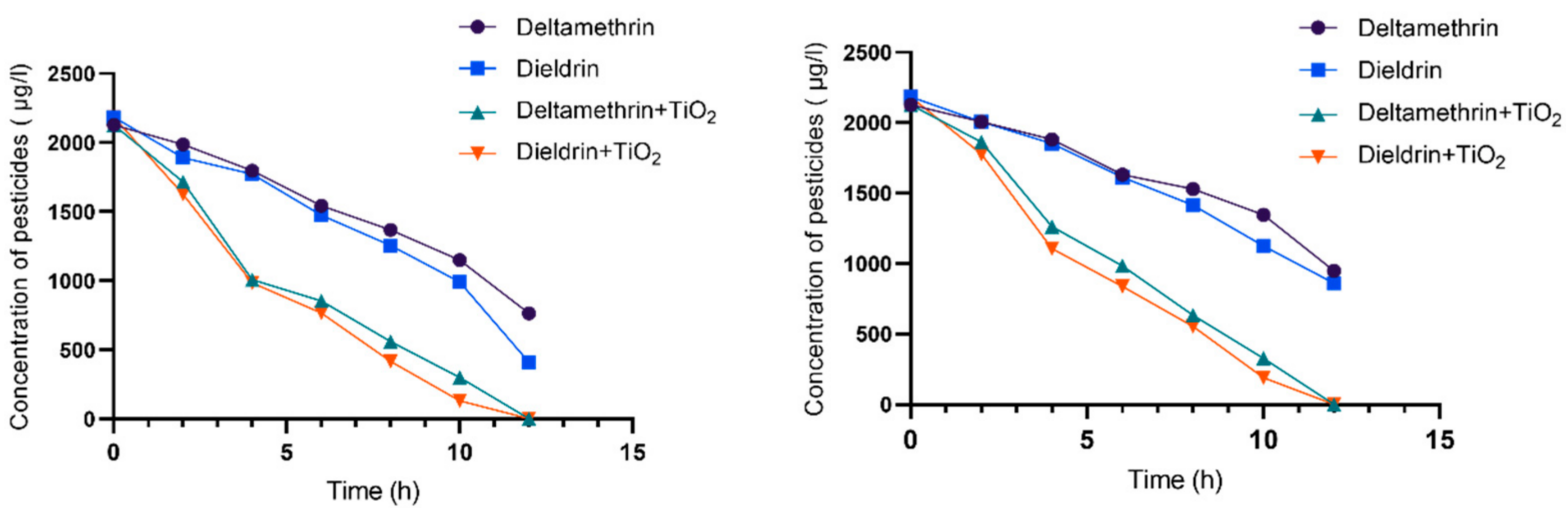

Figure 4. Concentration of pesticides ( $\mu \mathrm{g} / \mathrm{L}$ ) versus exposure time of UV radiation for photolysis process at $254 \mathrm{~nm}(\mathbf{l e f t})$ and $306 \mathrm{~nm}$ (right) in agricultural water with and without catalytic agent.

Experimental results indicated the abilities of the two tested wavelengths to promote pesticide photolysis. At both wavelengths investigated, deltamethrin was more degradable than dieldrin. In DW and WW, both pesticide degradations were observed after $4 \mathrm{~h}$ treatment at $254 \mathrm{~nm}$; after $4 \mathrm{~h}$ at $306 \mathrm{~nm}$, deltamethrin degradation was faster than that of dieldrin. However, in Ag.WW, both pesticide quantities were reduced from $2000 \mu \mathrm{g} / \mathrm{L}$ after the first $2 \mathrm{~h}$ at both wavelengths, suggesting higher UV efficiency in Ag.WW. After $2 \mathrm{~h}$, the dieldrin amount detected was the same at both wavelengths, and a higher degradation was observed for deltamethrin, especially at $306 \mathrm{~nm}$. 
The longer UV wavelength $(306 \mathrm{~nm})$ showed a higher capacity for pesticide degradation compared with $254 \mathrm{~nm}$, which is consistent with previous findings [38,39]; other pesticides are known to be degraded under UV exposure, suggesting that UV reactor usage might be a suitable approach for pesticide photolysis [40,41]. For example, in a previous study, the photolysis rate of deltamethrin and bifenthrin, another pyrethroid, under UV irradiation at 237, 240, and $246 \mathrm{~nm}$ was investigated by Tariq et al. [42]. Their findings revealed that deltamethrin was highly degradable in a time-dependent manner when subjected to UV irradiation in organic solvents. In the absence of UV light, the organophosphorus pesticide degradation rate was insignificant, indicating the significant role of UV in pesticide degradation [43].

This trend indicates that longer wavelengths lead to faster degradation as compared to that at shorter wavelengths, especially for deltamethrin. The destructive effect of UV on molecular bonds is well known; therefore, UV exposure should lead to increased pesticide degradation as time increases. Increased UV irradiation time increases the formation of free radicals in water, potentially leading to decomposition pesticide poisoning [44,45]. Furthermore, the difference in the degradation levels between deltamethrin and dieldrin may be due to differences in their structures.

\subsection{Photocatalysis Process}

The photo-remediation was performed with photocatalyst to study the effect of adding a catalytic amount of $\mathrm{TiO}_{2}$ on the pesticide photodegradations [41,44]. Photocatalytic pesticide residue breakdown by oxidation processes (AOP) is a modern approach that uses photons to degrade pesticides to $\mathrm{H}_{2} \mathrm{O}, \mathrm{CO}_{2}$, and inorganic compounds with no side effects [46]. However, catalyst type is an important factor in pesticide photodegradation [47]. Titanium dioxide $\left(\mathrm{TiO}_{2}\right)$ was used as a photocatalyst because it is effective in the decomposition of organic compounds and is more photochemically stable in water [48]. It is considered as a beneficial material for wastewater treatment because of its safe character; it is used in different applications, mainly in environmental remediation [49].

The catalytic effect of $\mathrm{TiO}_{2}(0.001 \mathrm{~g} / 10 \mathrm{~mL})$ added to aqueous media was tested when dieldrin and deltamethrin were exposed to ultraviolet irradiation. The degradation of pesticides with different wavelengths and exposure times was observed. The results are displayed in Figures 2-4, indicating degradation in a time-dependent manner, as was noticed for degradation without catalysis for both tested pesticides.

When $\mathrm{TiO}_{2}$ was applied in DW, UV treatment led to complete disappearance of pesticides at $306 \mathrm{~nm}$ at the end of treatment time; however, deltamethrin disappeared at $254 \mathrm{~nm}$ and only $49 \%$ of dieldrin was identified after $12 \mathrm{~h}$.

In addition, after adding the catalyst, it was noticed that the deltamethrin pesticide was not detected in all samples of water media of DW, WW, and Ag.WW after $12 \mathrm{~h}$ at any of the tested wavelengths, but only $49.9 \%, 49.1 \%$, and $40.5 \%$ of dieldrin were detected in water media of DW, WW, and Ag.WW, respectively, at $254 \mathrm{~nm}$, as well as only $32.6 \%$ and $24.3 \%$ of dieldrin were detected in WW and Ag.WW, respectively, when $306 \mathrm{~nm}$ was tested; however, after $12 \mathrm{~h}$, no pesticides residues were detected in DW.

Furthermore, it was observed that the percentage of pesticide degradation was higher when the catalyst was present compared to the previous experiments without the catalyst.

Hydrolysis levels in the presence of the catalyst were higher because the final concentrations of the pesticides were low compared to those after remediation without the catalyst. Hence, this catalyst has a role in improving the photolysis process. Thus, pesticides can be effectively destroyed by photocatalysis in the presence of $\mathrm{TiO}_{2}$ suspensions. The photo-remediation at both wavelengths of UV rays, with and without the catalyst, of the pesticides in different aqueous media as a function of time are displayed in Figures 2-4.

Effect of the addition of the photocatalyst on the degradation process has been reported in previous studies. Degradation of the compounds azinphos methyl, azinphos ethyl, disulfoton, dimethoate, and fenthion was detected in $\mathrm{TiO}_{2}$ suspensions under UV irradiation [50]. Deltamethrin degradation increased in the presence of catalytic $\mathrm{Cu}$ [42]. 
The same trend was also observed by Burrows et al. [51], who evaluated the degradation ratio of the pesticide malathion by applying natural solar illumination. The $2 \% \mathrm{WO}_{3} / \mathrm{TiO}_{2}$ photocatalyst displayed the best photocatalytic efficiency [52]. Phosalone photodegradation effectiveness was influenced by irradiation time and the amount of $\mathrm{TiO}_{2}$ present [43] According to Liu et al. [53], the $\mathrm{TiO}_{2} / \mathrm{HZSM}-11$ (30\%) catalyst was effective in solution; it maintained its photocatalytic ability after many cycles, and it could be removed easily from the treated solution and reused immediately, giving it a great advantage for photocatalytic wastewater treatment. A recent study noted that the breakdown of the pesticides profenofos and triazophos was enhanced by $\mathrm{TiO}_{2} / \mathrm{Ce}$ application on the leaves of Brassica chinensis [54]. Nguyen and Juang [55] noted that $\mathrm{TiO}_{2}$ use increased UV efficiency in p-chlorophenol degradation. Additionally, such a catalyst might be efficient under solar radiation, conserving electrical energy and consequently becoming an option for environmental remediation. Degradation rates were different in all studied conditions since wavelengths, exposure time, and solvent systems might affect the photodegradation [56]. It is worth noting the mechanism of photodegradation with and without a catalyst, since variations were noted between both conditions. In the remediation process without a photocatalyst, the pesticide molecules become excited by absorption of light energy of the UV radiation, causing homolysis, heterolysis, or photoionization. Whereas, in the process with a photocatalyst, the UV light energy will be absorbed by a semiconductor catalyst (titanium dioxide) to be photoexcited. However, a photoexcitation of the semiconductor catalyst occurs when the adsorbed light energy is greater than or at least equal to that of the gap between conduction and valence bands in the catalyst, leading to electron excitation to the conduction band (e-) and a positive hole $(\mathrm{h}+)$ in the valance band. Thus, oxidation-reduction reactions of the pesticide can be started by the radiation on the surface of semiconductor photocatalyst [52] On the other hand, hydrogen peroxide $\left(\mathrm{H}_{2} \mathrm{O}_{2}\right)$ as a powerful oxidant can be added to $\mathrm{TiO}_{2}$ catalyst to enhance the effectiveness of the treatment by generating electrons, which leads to avoid the recombination of $(\mathrm{e}-)-(\mathrm{h}+)$ pairs formed in the photocatalytic remediation [57]. This addition could reduce the effectiveness of the degradation process by modifying the photocatalyst surface by $\mathrm{H}_{2} \mathrm{O}_{2}$ adsorption [58] and the inhibition of generated ( $h+$ ) and reaction with hydroxyl radicals [59].

Additionally, studies on photoelectrochemical and catalysts applied for advanced treatment of wastewater are still at early stages despite the growing scientific and practical interest in this technology. Several recent studies have demonstrated that advanced oxidation processes (AOP) are more efficient for wastewater treatment, such as electrocatalysis, electro-fenton or photocatalysis, because hydroxyl radicals $(\mathrm{OH} \bullet)$ are strong oxidizing agents that are generated from AOP under mild conditions.

Thus, the AOP have recently attracted the attention of researchers because they allow for the continuous electrocatalytic generation of strong oxidizing species under mild conditions. Moreover, energy can be saved by using sunlight in photovoltaic electrolysis systems and using a catalyst to speed up reactions [60]. Generally, UV is a well-known disinfection process normally used for drinking water treatment via their breakdown of water $\mathrm{H}-\mathrm{O}$ bond. Consequently, water breakdown provides the strong oxidant $\mathrm{HO} \bullet$ that has high potential as a redox and organic pollutant oxidizer [61,62]; therefore, UV are efficient in pesticides' removal or reduction from water. Interestingly, although the mode of action for UV in photolysis could be the same in relation to both tested pesticides in the current study, pesticides in varied media with different organic components responded differently. The type of dissolved organic materials in water may affect the UV absorption and it is expected that higher organic compounds in water lead to a high ability in UV absorbance and, therefore, high degradation ability is expected. Ag.WW was approved as a good medium for pesticide removal when the catalyst was added, and such a finding could be explained by the fact that Ag.WW had high organic constituents that could be good substrates for pesticide residues' conjugation. Since organic molecules have a high tendency towards UV absorbance, high degradation ability is therefore expected for the organic-pesticides' conjugate [63]. 


\section{Conclusions}

As consequences of industrial wastes and agricultural usage, pesticide residues in water are considered as one of the most serious environmental problems worldwide and, therefore, an efficient method for their elimination is needed. This study demonstrated the efficiency of photocatalytic agents for analyzing pesticide residues, and this is the first study on pesticide degradation (dieldrin and deltamethrin) using UV in three different water media collected from Saudi Arabia. UV radiation was used at 254 and $306 \mathrm{~nm}$ to induce photodegradation with and without photocatalytic $\mathrm{TiO}_{2}$. The results showed that UV use led to successful pesticide photolysis. For both tested pesticides, UV at $306 \mathrm{~nm}$ increased photolysis in a time-dependent manner. The catalyst increased the efficiency of UV irradiation at both wavelengths. The photolysis conditions were effective for both insecticides. Deltamethrin showed a higher degradation than dieldrin under all studied conditions. The obtained results in this study are very encouraging, so further kinetics studies of photo-remediation are recommended.

Author Contributions: Conceptualization, M.H.E.-S. and M.A.; Data curation, K.A., A.S.A. and M.A.; Formal analysis, M.O.A. and M.A.; Methodology, M.H.E.-S. and M.A.; Project administration, M.H.E.S.; Resources, M.O.A., K.A. and A.S.A.; Supervision, M.H.E.-S., M.O.A. and M.A.; Writing-original draft, M.O.A., K.A., A.S.A. and M.A.-A.; Writing—review and editing, M.H.E.-S., M.O.A. and M.A. All authors have read and agreed to the published version of the manuscript.

Funding: This research was supported by the Chair of Environmental Pollution Research at Princess Nourah bint Abdulrahman University (Grant no. EPR023).

Data Availability Statement: All data supporting our findings are contained within the manuscript. Further details can be provided upon written request to the corresponding author.

Conflicts of Interest: The authors declare no conflict of interest.

\section{References}

1. Cesco, M.; Lucini, L.; Miras-Moreno, B.; Borruso, L.; Mimmo, T.; Pii, Y.; Puglisi, E.; Spini, G.; Taskin, E.; Tiziani, R.; et al. The hidden effects of agrochemicals on plant metabolism and root-associated microorganisms. Plant Sci. 2021, 311, 111012. [CrossRef]

2. WHO. Health Topics: Pesticides. 2020. Available online: https://www.who.int/topics/pesticides/en/ (accessed on 1 February 2020).

3. Eddleston, M.; Bateman, D.N. Pesticides. Medicine 2012, 40, 147-150. [CrossRef]

4. Eddleston, M. Pesticides. Medicine 2016, 44, 193-196. [CrossRef]

5. Verhaelen, K.; Bouwknegt, M.; Rutjes, S.; Husman, A. Persistence of human norovirus in reconstituted pesticides- Pesticide application as a possible source of viruses in fresh produce chains. Int. J. Food Microbiol. 2013, 160, 323-328. [CrossRef]

6. Cooper, J.; Dobson, H. The benefits of pesticides to mankind and the environment. Crop Prod. 2007, 26, 1337-1348. [CrossRef]

7. Codex. Code of Hygienic Practice for Fresh Fruits and Vegetables; (Revised 2010 (New Annex III for Fresh Leafy Vegetables)). 2003. Available online: https:/ /www.ifsh.iit.edu/sites/ifsh/files/departments/ssa/pdfs/codex2003_053e.pdf (accessed on 21 October 2021).

8. Oller, I.; Malato, S.; Sánchez-Peérez, J.A.; Maldonado, M.I.; Gasso, R. Detoxification of wastewater containing five common pesticides by solar AOPs-biological coupled system. Catal. Today 2007, 129, 69-78. [CrossRef]

9. Begum, G. Carbofuran insecticide induced biochemical lalterations in liver and muscle tissues of the fish Clarias batrachus (Linnaeus) and recovery response. Aquat. Toxicol. 2004, 66, 83-92. [CrossRef] [PubMed]

10. Mahmood, A.; Malik, R.; Li, J.; Zhan, G. Levels, distribution profile, and risk assessment of polychlorinated biphenyls (PCBs) in water and sediment from two tributaries of the River Chenab, Pakistan. Environ. Sci. Pollut. Res. 2014, 21, 7847-7855. [CrossRef]

11. Fantke, P.; Friedrich, R.; Jolliet, O. Health impact and damage cost assessment of pesticides in Europe. Environ. Int. 2012, 49, 9-17. [CrossRef]

12. Costa, L. The neurotoxicity of organochlorine and pyrethroid pesticides (Chapter 9). Handb. Clin. Neurol. 2015, 131, 135-148. [CrossRef]

13. Hatcher, J.; Richardson, J.; Guillot, T.; McCormack, A.; Di Monte, A.; Jones, D.; Pennell, K.; Miller, G. Dieldrin exposure induces oxidative damage in the mouse nigrostriatal dopamine system. Exp. Neurol. 2007, 204, 619-630. [CrossRef]

14. Sava, V.; Velasquez, A.; Song, S.; Sanchez-Ramos, J. Dieldrin Elicits a Widespread DNA Repair and Antioxidative Response in Mouse Brain. J. Biochem. Mol. Toxicol. 2007, 21, 3. [CrossRef]

15. Hashimoto, Y. Dieldrin Residue in the Soil and Cucumber from Agricultural Field in Tokyo. J. Pestic. Sci. 2005, 30, 397-402. [CrossRef]

16. Maldonado-Reyes, A.; Montero-Ocampo, C.; Solorza-Feria, O. Remediation of drinking water contaminated with arsenic by electro-removal process using different metal electrodes. Environ. Monit. 2007, 9, 1241-1247. [CrossRef] [PubMed] 
17. Saqib, T.; Naqvi, S.; Siddiqui, P.; Azmi, M. Detection of pesticide residues in muscles, liver and fat of 3 species of Labeo found in Kalri and Haleji lakes. J. Environ. Biol. 2005, 26, 433-438.

18. Al-Wabel, M.; El-Saeid, M.H.; Usman, A.R.; Al-Turki, A.M.; Ahmad, M.; Hassanin, A.S.; El-Naggar, A.H.; Alenazi, K.K. Identification, Quantification, and Toxicity of PCDDs and PCDFs in Soils from Industrial Areas in the Central and Eastern Regions of Saudi Arabia. Bull. Environ. Contam. Toxicol. 2016, 96, 622-629. [CrossRef]

19. El-Saeid, M.; Al-Dosari, S. Monitoring of pesticide residues in Riyadh dates by SFE, MSE, SFC, and GC techniques. Arab. J. Chem. 2010, 3, 179-186. [CrossRef]

20. Ahmed, T.; Rafatullah, M.; Ghazali, A.; Sulaiman, O.; Hashim, R.; Ahmad, A. Removal of pesticides from water and wastewater by different adsorbents: A review. J. Environ. Sci. Health Part C Environ. Carcinog. Ecotoxicol. Rev. 2010, 28, 231-271. [CrossRef]

21. Ali, I.; Gupta, V.K. Advances in water treatment by adsorption technology. Nat. Protocol. 2006, 1, 2661-2667. [CrossRef] [PubMed]

22. Ali, I.; Khan, T.A.; Asim, M. Removal of arsenic from water by electrocoagulation and electrodialysis techniques. Sepn. Purif. Rev. 2011, 40, 25-42. [CrossRef]

23. Ali, I.; Khan, T.; Asim, M. Removal of arsenate from groundwater by electrocoagulation method. Environ. Sci. Pollut. Res. 2012, 19, 1668-1676. [CrossRef]

24. Ali, I.; Basheer, A.; Mbianda, X.; Burakov, A.; Galunin, E.; Burakova, I.; Mkrtchyan, E.; Tkachev, A.; Grachev, V. Graphene based adsorbents for remediation of noxious pollutants from wastewater. Environ. Int. 2019, 127, 160-180. [CrossRef]

25. Saleh, I.; Zouari, N.; Al-Ghouti, M. Removal of pesticides from water and wastewater: Chemical, physical and biological treatment approaches. Environ. Technol. Innov. 2020, 19, 101029. [CrossRef]

26. Oturan, M.; Aaron, J. Advanced Oxidation Processes in Water/Wastewater Treatment: Principles and Applications. A Review. Crit. Rev. Environ. Sci. Tech. 2014, 44, 2577-2641. [CrossRef]

27. Zhou, J.; Liu, Z.; She, P.; Ding, F. Water removal from sludge in a horizontal electric field. Dry. Technol. 2001, 19, 627-638. [CrossRef]

28. Baghirzade, B.; Yetis, U.; Dilek, F. Imidacloprid elimination by $\mathrm{O}_{3}$ and $\mathrm{O}_{3} / \mathrm{UV}$ : Kinetics study, matrix effect, and mechanism insight. Environ. Sci. Pollut. Res. 2021, 28, 24535-24551. [CrossRef] [PubMed]

29. Shifu, C.; Gengyu, C. Photocatalytic degradation of organophosphorus pesticides using floating photocatalyst $\mathrm{TiO}_{2} . \mathrm{SiO}_{2} /$ beads by sunlight. Sol. Energy 2005, 79, 1-9. [CrossRef]

30. Zhang, R.; Yang, Y.; Huang, C.; Zhao, L.; Sum, P. Kinetics and modeling of sulfonamide antibiotic degradation in wastewater and human urine by $\mathrm{UV} / \mathrm{H}_{2} \mathrm{O}_{2}$ and UV/PDS. Water Res. 2016, 103, 283-292. [CrossRef] [PubMed]

31. Cassano, D.; Zapata, A.; Brunetti, G.; Del Moro, G.; Di Iaconi, C.; Oller, I.; Malato, S.; Mascolo, G. Comparison of several combined/integrated biological-AOPs setups for the treatment of municipal landfill leachate: Minimization of operating costs and effluent toxicity. Chem. Eng. J. 2011, 172, 250-257. [CrossRef]

32. Katagi, T. Direct photolysis mechanism of pesticides in water. J. Pestic. Sci. 2018, 43, 57-72. [CrossRef]

33. Matsumoto, K.; Kawanaka, Y.; Yun, S.J.; Oyaizu, H. Bioremediation of the organochlorine pesticides, dieldrin and endrin, and their occurrence in the environment. Appl. Microbiol. Biotechnol. 2009, 84, 205-216. [CrossRef] [PubMed]

34. Ismail, B.S.; Mazlinda, M.; Tayeb, M.A. The Persistence of Deltamethrin in Malaysian Agricultural Soils. Sains Malays. 2015, 44, 83-89. [CrossRef]

35. Lehtola, M.J.; Miettinen, I.T.; Vartiainen, T.; Rantakokko, P.; Hirvonen, A.; Martikainen, P.J. Impact of UV disinfection on microbiallyavailable phosphorus, organic carbon, and microbial growth in drinking water. Water Res. 2003, 37, 1064-1070. [CrossRef]

36. Li, X.; Cai, M.; Wang, L.; Niu, F.; Yang, D.; Zhang, G. Evaluation survey of microbial disinfection methods in UV-LED water treatment systems. Sci. Total. Environ. 2019, 659, 1415-1427. [CrossRef] [PubMed]

37. Sanz, J.; Lombraña, J.I.; Ma De Luis, A.; Varona, F. UV $/ \mathrm{H}_{2} \mathrm{O}_{2}$ chemical oxidation for high loaded effluents: A degradation kinetic study of las surfactant wastewaters. Environ. Technol. 2008, 247, 903-911. [CrossRef]

38. El-Saeid, M.; Al-Turki, A.; Nadeem, M.; Hassanin, A.; Al-Wabel, M. Photolysis degradation of polyaromatic hydrocarbons (PAHs) on surface sandy soil. Environ. Sci. Pollut. Res. 2015, 22, 9603-9616. [CrossRef]

39. EL-Saeid, M.H.; Alotaibi, M.O.; Alshabanat, M.; AL-Anazy, M.M.; Alharbi, K.R.; Altowyan, A.S. Impact of Photolysis and TiO 2 on Pesticides Degradation in Wastewater. Water 2021, 13, 655. [CrossRef]

40. Aaron, J.; Oturan, M. New photochemical and electrochemical methods for the degradation of pesticides in aqueous media. Turk. J. Chem. 2001, 25, 509-520.

41. Shayeghi, M.; Dehghani, M.H.; Alimohammadi, M.; Goodini, K. Using Ultraviolet Irradiation for Removal of Malathion Pesticide in Water. J. Arthropod-Borne Dis. 2012, 6, 45-53. [PubMed]

42. Tariq, S.R.; Ahmed, D.; Farooq, A.; Rasheed, S.; Mansoor, M. Photodegradation of bifenthrin and deltamethrin-effect of copper amendment and solvent system. Environ. Monit. Assess. 2017, 189, 71. [CrossRef]

43. Daneshvar, N.; Hejazi, M.; Rangarangy, B.; Khataee, A. Photocatalytic Degradation of an Organophosphorus Pesticide Phosalone in Aqueous Suspensions of Titanium Dioxide. J. Environ. Sci. Health Part B 2004, 39, 285-296. [CrossRef] [PubMed]

44. Xie, Q.; Chen, J.; Shao, J.; Chen, C.; Zhao, H.; Hao, C. Important role of reaction field in photodegradation of deca-bromodiphenyl ether: Theoretical and experimental investigations of solvent effects. Chemosphere 2009, 76, 1486-1490. [CrossRef] [PubMed]

45. Saqib, N.; Adnan, R.; Shah, I. A mini-review on rare earth metal-doped $\mathrm{TiO}_{2}$ for photocatalytic remediation of wastewater. Environ. Sci. Pollut. Res. 2016, 23, 15941-15951. [CrossRef] 
46. Thiruvenkatachari, R.; Vigneswaran, S.; Shik, M. A review on UV/TiO 2 photocatalytic oxidation process. Korean J. Chem. Eng. 2008, 25, 64-72. [CrossRef]

47. Mecha, A.C.; Chollom, M.N. Photocatalytic ozonation of wastewater: A review. Environ. Chem. Lett. 2020, 18, 1491-1507. [CrossRef]

48. Ramos-Delgado, N.A.; Gracia-Pinilla, M.A.; Maya-Trevino, L.; Hinojosa-Reyes, L.; Guzman-Mar, J.L.; Hernández-Ramírez, A. Solar photocatalytic activity of $\mathrm{TiO}_{2}$ modified with $\mathrm{WO}_{3}$ on the degradation of an organophosphorus pesticide. J. Hazard. Mater. 2013, 263, 36-44. [CrossRef]

49. Yavg, V. Photocatalytic Degradation of Selected Organophosphorus Pesticides Using Titanium Dioxide and UV Light. In Titanium Dioxide: Material for a Sustainable Environment; Additional information is available at the end of the chapter; Petsas, A.S., Vagi, M.C., Eds.; IntechOpen: London, UK, 2018; p. 241. [CrossRef]

50. Montañez, J.; Gómez, S.; Santiago, A.; Pierella, L. TiO 2 Supported on HZSM-11 Zeolite as Efficient Catalyst for the Photodegradation of Chlorobenzoic Acids. J. Braz. Chem. Soc. 2015, 26, 1191-1200. [CrossRef]

51. Burrows, H.; Canle, M.; Santaballa, J.; Steenken, S. Reaction pathways and mechanisms of photodegradation of pesticides. J. Photochem. Photobiol. B Biol. 2002, 67, 71-108. [CrossRef]

52. Konstantinou, I.; Albanis, T. Photocatalytic transformation of pesticides in aqueous titanium dioxide suspensions using artificial and solar light: Intermediates and degradation pathways. Appl. Catal. B Environ. 2003, 42, 319-335. [CrossRef]

53. Liu, S.; Liu, G.; Feng, Q. Al-doped $\mathrm{TiO}_{2}$ mesoporous materials: Synthesis and photodegradation properties. J. Porous Mater. 2010, 17, 197-206. [CrossRef]

54. Liu, X.; Zhan, Y.; Zhang, Z.; Pan, L.; Hu, L.; Liu, K.; Zhou, X.; Bai, L. Photocatalytic Degradation of Profenofos and Triazophos Residues in the Chinese Cabbage, Brassica chinensis, Using Ce-Doped $\mathrm{TiO}_{2}$. Catalysts 2019, 9, 294. [CrossRef]

55. Nguyen, A.T.; Juang, R. Photocatalytic degradation of p-chlorophenol by hybrid $\mathrm{H}_{2} \mathrm{O}_{2}$ and $\mathrm{TiO}_{2}$ in aqueous suspensions under UV irradiation. J. Environ. Manag. 2015, 147, 271-277. [CrossRef] [PubMed]

56. Sarkouhi, M.; Shamsipur, M.; Hassan, J. Metal ion promoted degradation mechanism of chlorpyrifos and phoxim. Arab. J. Chem. 2016, 9, 43-47. [CrossRef]

57. Miguel, N.; Ormad, M.P.; Mosteo, R.; Overlleiro, J. Photocatalytic Degradation of Pesticides in Natural Water: Effect of Hydrogen Peroxide. Int. J. Photoenergy 2012, 2012, 371714. [CrossRef]

58. Pelizzetti, E. Concluding remarks on heterogeneous solar photocatalysis. Sol. Energy Mater. Sol. Cells 1995, 38, 453-457. [CrossRef]

59. Malato, S.; Fernández-Ibáñez, P.; Maldonado, M.I.; Blanco, J.; Gernjak, W. Decontamination and disinfection of water by solar photocatalysis: Recent overview and trends. Catal. Today 2009, 147, 1-59. [CrossRef]

60. Mousset, E.; Dionysiou, D.D. Photoelectrochemical reactors for treatment of water and wastewater: A review. Environ. Chem. Lett. 2020, 18, 1301-1318. [CrossRef]

61. Yang, L.; Zhang, Z. Degradation of six typical pesticides in water by VUV/UV/chlorine process: Evaluation of the synergistic effect. Water Res. 2019, 161, 439-447. [CrossRef]

62. Lopez-Alvarez, B.; Villegas-Guzman, P.; Peñuela, G.A.; Torres-Palma, R.A. Degradation of a Toxic Mixture of the Pesticides Carbofuran and Iprodione by $\mathrm{UV} / \mathrm{H}_{2} \mathrm{O}_{2}$ : Evaluation of Parameters and Implications of the Degradation Pathways on the Synergistic Effects. Water Air Soil Pollut. 2016, 227, 215. [CrossRef]

63. Konstantinou, I.K.; Zarkadis, A.K.; Albanis, T.A. Photodegradation of Selected Herbicides in Various Natural Waters and Soils under Environmental Conditions. J. Environ. Qual. 2001, 30, 121-130. [CrossRef] 